\title{
Novos Movimentos Sociais E O MODELO Procedimental de Democracia de JÜRGEN HABERMAS
}

Resumo: $A$ Teoria da Ação Comunicativa, de Jürgen Habermas, é um valioso instrumental teórico para a análise da nova ordem de acontecimentos que emerge no mundo contemporâneo. Suas ambiciosas propostas analiticas vêm acompanhadas de um modelo de democracia radical que contempla a constituição da esfera pública política sobre novas bases, dinamizada por novos mecanismos e orientada para diferentes fins. $\mathrm{O}$ objetivo deste artigo é pensar como esse modelo habermasiano, enriquecido pelas contribuiçōes de Andrew Arato e Jean Cohen sobre a teoria da sociedade civil, pode ser aplicado para o estudo dos novos movimentos sociais envolvidos na construção de tal modelo de democracia radical.

UNITERMOS: Teoria da ação comunicativa; teoria democrática; novos movimentos sociais.

\section{INTRODUÇÃO}

A emancipação da sociedade e do indivíduo sempre foi a motivação maior dos estudos de Horkheimer, Adorno e Marcuse, os predecessores de Jürgen Habermas no Instituto de Pesquisa Social de Frankfurt. $\mathrm{O}$ tom negativo com que os principais nomes da Escola de Frankfurt imprimiam aos seus trabalhos declarava a indignação com que viam a quase impossibilidade, tanto teórica como política, de, a partir dos 
aspectos predominantes da sociedade industrial, verem realizadas as promessas do projeto do Iluminismo. Suas reflexões revelam que a preponderância da Razão na organização da vida social, ao invés de ter livrado o homem do obscurantismo, enclausurou-o numa concepção de mundo ainda mais perversa que aquela que o prendia aos desígnios e vontades divinas. O Iluminismo trouxe, em si, os próprios elementos aprisionantes contra os quais justificou sua ascensão.

Muito significativas para a postura teórico-política adotada pela primeira geração da Escola de Frankfurt foram as três ordens de acontecimentos seguintes por ela vivenciada: em primeiro lugar, o stalinismo, na União Soviética, que pôs abaixo a esperança de uma nova experiência social, que pudesse ser alternativa ao capitalismo, em decorrência da forte repressão política operada pelo gigantesco aparato burocrático que se constituiu após a revolução bolchevique, repressão essa ainda mais intensa que em vários dos países capitalistas seus contemporâneos; em segundo lugar, a ascensão do nazismo e sua legitimação por parte sensível da população européia, ávida por um grande ditador, levando a dominação sócio-político-econômica às últimas conseqüências; e, finalmente, a pacífica mas também intensa dominação ideológica imprimida pela indústria cultural, observada de perto pelos próprios pensadores da Escola no decorrer dos 15 anos que estiveram nos Estados Unidos (Freitag, 1986 e Habermas, 1990).

O mundo contemporâneo, na análise da Escola, encaminhava-se de tal maneira para uma situação em que sua dinâmica passaria a ser determinada pela razão instrumental que, cada vez mais, sobraria menos espaço para a realização de atividades autônomas e emancipadoras pelo homem. Na obra Eclipse da Razão (Horkheimer, 1976), Horkheimer aponta para o fato de que a expansão do horizonte da atividade e do pensamento humanos decorrente das conquistas do conhecimento técnico trazia, ao mesmo tempo, um estreitamento da autonomia do homem, da sua capacidade de opor resistência ao "crescente mecanismo de 
manipulação de massas" (Horkheimer, 1976, p.6). É isso que, para o autor, faz com que o avanço técnico venha acompanhado por um não menos intenso processo de desumanização. "Assim, o progresso ameaça anular o que se supõe ser o seu próprio objetivo: a idéia de homem" (Horkheimer, 1976, p.6).

Qual homem resulta desse processo destrutivo? $O$ resultado só poderia ser uma sociedade em que seus homens têm uma única dimensão, voltada para a produção e reprodução do aparato econômicoadministrativo, tal e qual demonstra Marcuse em sua obra One Dimensional Man (Marcuse, 1968). Os pensamentos, o linguajar, a ocupação do tempo livre, a sexualidade, enfim, todas as esferas da vida humana passam a ser determinadas pelos fins impostos pela avançada civilização industrial, isto é, os fins da racionalidade tecnológica. Com isso, até mesmo a interioridade [inner], que já chegou a se constituir como um espaço privado no qual um determinado indivíduo se diferenciava dos demais, perde sua importância na determinação dos pensamentos e comportamentos dos indivíduos. Enfim, há uma coisificação quase que completa do homem contemporâneo.

O universo tecnológico torna-se, para Marcuse, um universo político na sociedade industrial avançada: a racionalidade tecnológica tornase o melhor veículo de dominação na medida em que, sob a aparência de neutralidade, consegue fazer crer que dela depende a continuidade do bem-estar da população. Encobertas por esse 'manto transparente', as diferenças econômico-sociais tornam-se imperceptíveis, e o potencial político contestatório é reprimido de forma pacífica.

A força com que esses aspectos aparecem faz com que os autores aprofundem ainda mais o alcance teórico na investigação das tendências que acabaram ganhando sua plenitude na sociedade industrial. $\mathrm{Na}$ obra Dialética do Esclarecimento (Horkheimer \& Adorno, 1985), vão à Odisséia de Homero buscar as raízes do Iluminismo e, lá, descobrem que, se esse projeto se justificou afirmando derrubar o mito, é preciso dizer que ele 
mesmo é um mito. Ulisses, o herói homérico, "revela-se precisamente como um protótipo do indivíduo burguês cujo conceito tem origem naquela auto-afirmação unitária que encontra seu modelo mais antigo no herói errante" (Horkheimer \& Adorno, 1985, p.53). Os autores entendem com isso que

"as linhas da razão, da liberdade, da civilidade burguesa se estendem incomparavelmente mais longe do que supoem os bistoriadores que datam o conceito burguês tão-somente do fim do feudalismo medieval" (Horkheimer \& Adorno, 1985, p.54).

Ainda a esse respeito, vale dizer que, em Horkheimer \& Adorno (1985), a tendência à racionalidade instrumental parece estar no próprio fundamento do estranhamento do homem com seu meio circundante. Nesse sentido, os autores colocam que:
"A sociedade é um prolongamento da natureza ameaçadora enquanto compulsão duradoura e organizadaque, reproduzindo-se no individuo como uma autoconservação conseqüente, repercute sobre a natureza enquanto dominação social da natureza." (Horkheimer \& Ador- no, 1985 , p. 169)

A diferença do atual momento é que, enquanto em 'tempos anteriores' da sociedade os rituais mágicos intentavam dominar a natureza através da sua imitação corporal, hoje, é a técnica que efetua a necessidade de autoconservação, só que, conforme definem os autores, através da automatização dos processos espirituais, isto é, através de sua transformação em processos cegos, irracionais.

Adicionando todas essas considerações à violência com que tanto Horkheimer e Adorno, como também Marcuse argumentam contra o caráter obscurecedor do pensamento positivista, e a própria denúncia à fetichização do pensamento dialético, ${ }^{1}$ compreende-se o porquê do

${ }^{1}$ A esse respeito ver Adorno, 1986, p.66.

Temáticas, Campinas, 4(8):143-166, jul./dcz. 1996 
'labirinto teórico-político' em que a Escola de Frankfurt adentrou. Como, a partir daí, imersos nesse contexto, vislumbrar a possibilidade efetiva de uma emancipação da sociedade e do indivíduo? Como levar adiante o projeto da modernidade, em que se dá o processo de individuação, um pressuposto para a autodeterminação dos destinos do indivíduo sem que isso signifique uma desagregação da sociedade?

\section{A MudanÇa Paradigmática}

Ao lado de Alfred Schmidt e Tiedemann, Jürgen Habermas forma o quadro principal da segunda geração da Escola de Frankfurt. Enquanto os dois primeiros se dedicaram à preservação do pensamento de Benjamin, Horkheimer, Adorno e Marcuse a partir de um cuidadoso trabalho de revisão de textos da Teoria Crítica que culminou na publicação de estudos inéditos da primeira geração (Freitag, 1986), Habermas levou adiante o 'projeto crítico' teórico-político da Escola, de forma bastante original e ousada, operando, inclusive, uma 'virada paradigmática'.

Habermas entende que o programa da primeira Teoria Crítica fracassou em decorrência de um esgotamento do paradigma da filosofia da consciência, por cle definido como sendo aquele em que o sujeito se representa nos objetos e se forma no enfrentamento com eles por meio da ação. A própria postura daqueles autores de se deterem à análise dos aspectos negativos da sociedade industrial avançada atesta sua resignação frente à impossibilidade de propor alternativas diante do reconhecimento da crise da razão objetiva e do caráter identificante - e portanto autoritário, uma vez que desconsiderador das particularidades em nome da totalidade - dos grandes sistemas filosóficos. Qualquer formulação correria o risco de reproduzir teórica e politicamente a atual situação de aprisionamento em que o homem da sociedade industrial avançada se encontra, situação agravada pela falsa noção de que o progresso técnico 
indiscriminado, não só possibilita, como é o principal artífice da emancipação do homem. Certamente, em decorrência da descrença nas possibilidades críticas da elaboração conceitual, Horkheimer, no final de sua vida, voltou-se à religião e Adorno, nos últimos estudos, à música, como saídas alternativas de leituras não-reificadas da realidade social (Freitag, 1986 e Assoun, 1991). Diz Habermas que a primeira geração não podia mais, por suas próprias forças, desenvolver a idéia de uma razão capaz de efetivar o projeto do Iluminismo, caindo, então, na conhecida postura pessimista frente à realidade, postura que nos faz lembrar da afinidade que o jovem Horkheimer tinha com os escritos de Schopenhauer.

Posto isso, o autor de Teoria da Afão Comunicativa coloca-se duas tarefas teórico-metodológicas: superar e relativizar a idéia da vigência de uma razão subjetiva na modernidade. Essa superação se dá a partir da ampliação do conceito de ação (para além da escolha estratégicoinstrumental de meios que permitam atingir, com maior eficácia, fins determinados de forma desvinculada de valores morais e estéticos): a ação comunicativa, cuja motivação está na busca racional de um entendimento intersubjetivo. Esta primeira tarefa marca, portanto, a virada em direção à filosofia da linguagem, fortemente inspirada por seus estudos sobre Mead: esse sociólogo, ao reconstruir o campo de transição desde o animal até o homem na forma de uma seqüência de formas de interação, entende que a ação comunicativa é antropologicamente fundamental no sentido de que as estruturas de interação regidas por normas lingüisticamente mediadas definem a situação de partida dos desenvolvimentos culturais. A segunda tarefa consiste na integração entre a teoria de sistemas e a teoria da ação, sem que isso signifique a absorção de uma pela outra.

Obviamente, as duas tarefas encontram-se necessariamente interligadas uma vez que Habermas analisa a sociedade simultaneamente como sistema e mundo da vida, isto é, analisa simultaneamente os aspectos de reprodução material da vida social e os aspectos de reprodução cultural, 
integração social e socialização da vida humana. Conforme o autor, há, na vida social, o nível sistêmico, vinculado à reprodução material, que aparece regido, fundamentalmente, pela racionalidade instrumental, no intercâmbio dos homens com a natureza e dos homens entre si; e o nível do mundo da vida, que é palco para os processos de reprodução cultural - o acervo total de saber que dá referência às relações sociais -, de integração social - as ordenações legitimamente reguladas dos homens entre si -, e de socialização - que, a partir de capacidades comunicativas subjetivas, possibilita aos indivíduos a busca de suas identidades.

No processo de racionalização das sociedades, Habermas afirma ter ocorrido uma complexificação e diferenciação dos componentes estruturais da esfera social sistêmica (economia e administração) e uma diferenciação e racionalização das estruturas do mundo da vida (cultura, sociedade e personalidade) de tal forma que a dinâmica de cada um desses elementos passou a se dar de forma autônoma. Sem ainda se aprofundar nas conseqüências desse processo, vale dizer que:

"Quanto mais se diferenciam os componentes estruturais do mundo da vida e os componentes que contribuem à sua manutenção, tanto mais submetidos ficam os contextos de interafão às condiföes de um entendimento racionalmente motivado, isto é, às condições de formafão de um consenso que em última instância se baseie na autoridade do melhor argumento." (Habermas, 1990, p.205-6)

Assim é que, operando essa 'virada paradigmática', Habermas entende dar seqüência ao inacabado projeto da modernidade vislumbrando, a partir dai, uma alternativa político-institucional - conforme mais tarde veremos - que a primeira geração de Frankfurt não acreditava ser possível, além de um instrumental teórico capaz de melhor perceber o processo evolutivo dos sistemas sociais e das formas de integração social ao longo da história da humanidade, desde as sociedades 'arcaicas' até as sociedades modernas. 


\section{EVOLUÇÃo SISTÊMICA E MUdANÇA INSTITUCIONAL}

Habermas, na análise da evolução organizacional das sociedades, inverte a consideração do Marx de $A$ Ideologia Alemã (1991), para quem a produção material dos meios de vida $\mathrm{e}$ as diferentes fases da divisão do trabalho a ela vinculadas determinam a relação dos indivíduos entre si e são a base de todas as outras formas de intercâmbio (Marx \& Engels, 1991, p.28). O autor de Teoria da Ação Comunicativa sustenta que, ao invés das estruturas do mundo da vida dependerem, em suas mutações, dos incrementos da complexidade do sistema, são os aumentos das complexidades sistêmicas que dependem da diferenciação e racionalização estrutural do mundo da vida. Nesse sentido, cada novo mecanismo de diferenciação sistêmica que consiga primazia na organização social tem, necessariamente, que ficar ancorado no mundo da vida.

Nas sociedades 'arcaicas', sistema e mundo da vida encontram-se de tal maneira acoplados que é o sistema de parentesco a instituição total que regula todas as interações possíveis. A realização de intercâmbio de produtos e mulheres não tem, dessa forma, uma motivação econômica; na verdade, trata-se, sim, de um produto da coação normativa, com a finalidade de reforçar a integração social, impedindo que cada grupo produtor particular se auto-satisfaça mediante o consumo dos próprios bens e produtos.

Mas, a tendência evolutiva, como anteriormente chamamos a atenção, aponta para a diferenciação e racionalização das estruturas do mundo da vida que provocam mudanças institucionais que, no limite, tendem à autonomização da dinâmica dos subsistemas centrados na reprodução material.

As transformações por que passam as sociedades 'arcaicas' são ilustrativas a esse respeito: no momento em que grupos unilineares de descendência começam a se estratificar e a criar gradientes de poder, os 
sistemas de parentesco deixam de organizar igualitariamente as sociedades para garantir status a alguns de seus membros (Habermas, 1990).

Nas sociedades modernas, a diferenciação c racionalização estrutural do mundo da vida atinge um nível tal que os âmbitos de ação orientados ao êxito se separam dos âmbitos de ação orientados ao entendimento, abrindo caminho para a formação de subsistemas de ação racional com respeito a fins autonomizados. Com isso, o comércio social ocorre desacoplado de normas e valores, ficando coordenado através de meios de controle 'deslingüistizados'. No mundo moderno, moral e direito se desconectam e perdem a qualidade de controle interno do comportamento dos indivíduos. $\mathrm{O}$ processo em que o direito positivo substitui as normas tradicionais na regulamentação das relações sociais é chamado por Habermas de 'juridificação' dos âmbitos de ação estruturados comunicativamente.

Nesse processo, ocorre o que Habermas qualifica como sendo uma 'generalização dos valores' com uma conseqüente necessidade de universalização dos meios de orientação das ações. Essa necessidade de universalização dos meios de orientação faz com que a ação comunicativa fique cada vez mais desligada dos padrões normativos concretos, tradicionais, de forma que a 'tarefa' de integração social e formação de identidades se desloque do consenso de base religiosa (típico nas sociedades 'arcaicas') para os processos lingüisticos de formação racional de consenso. Entretanto, este mesmo processo aumenta em muito os riscos de desentendimentos dado que, diferentemente das sociedades 'arcaicas', o mundo da vida racionalizado não garante, de antemão, convicções inquestionáveis das quais os participantes podem fazer uso direto nas interações. Uma forma de evitar tais desentendimentos é, exatamente, substituir os meios de coordenação lingüísticos pelos meios de controle 'deslingüistizados', que são o dinheiro e o poder: esses meios codificam as interações em ações racionais com respeito a fins, passíveis, portanto, 
de serem calculadas e, no caso de infrações, de serem os indivíduos mais facilmente ressarcidos.

"Com isso, o direito se transforma em um poder externo, imposto desde fora, até o ponto em que o direito coativo moderno, sancionado pelo Estado, se converte em uma instituição desconectada dos motivos éticos daqueles para quem rege o sistema jurídico, e necessita só de uma obediência abstrata ao sistema de normas. '(Habermas, 1990, p.247)

O resultado disso não poderia ser diferente: ocorre uma desvalorização do contexto do mundo da vida em seu papel de coordenação das ações tendendo, inclusive, para uma situação em que os imperativos sistêmicos, já sem as contingências dos imperativos da integração social, passam a instrumentalizar as próprias estruturas do mundo da vida. É esse o processo que Habermas chama de colonização sistêmica do mundo da vida, que vem provocar perturbações na reprodução simbólica do mundo da vida na medida em que "os desequilíbrios críticos da reprodução material (isto é, as crises de controle) só podem ser evitados ao preço de perturbações na reprodução simbólica do mundo da vida" (Habermas, 1990, p.422-3).

Mas, é preciso que se diga, de alguma forma, os âmbitos de ação comunicativamente estruturados impuseram resistências ao processo de colonização interna do mundo da vida ao longo do processo de 'juridificação'. Vale aqui apontar para o fato de que, frente a esse processo de 'juridificação', tais âmbitos de ação se constituem em duas formas: na forma de esfera da vida privada, que tem na família seu núcleo institucional; na forma de esfera da opinião puiblica, onde se movem os cidadãos. As progressivas conquistas dessas esferas, no sentido de protegerem-se frente aos imperativos sistêmicos, podem ser sentidas ao longo das quatro jornadas de 'juridificação' apontadas por Habermas: o Estado Burguês, ordem política dentro da qual se efetua a transformação da sociedade estamental em sociedade aquisitiva do capitalismo. Nesse primeiro 
momento se dá a institucionalização do direito privado e do direito público, responsáveis, respectivamente, pela institucionalização do mercado de trabalho e pela legitimação do poder estatal soberano como única fonte de dominação política; aqui, o mundo da vida e sua dinâmica aparecem relegados apenas à esfera da vida privada.

O segundo momento é o Estado Burguês de Direito, quando os cidadãos passam a ser dotados de direitos subjetivo-jurídicos, podendo fazer-se valer frente ao soberano, em cujas decisões, porém, ainda não têm participação. Aqui, o mundo da vida já passa a ser objeto de reconhecimento jurídico e de proteção na medida em que as garantias relativas à vida, à liberdade e à propriedade tornam-se normas institucionais.

O terceiro momento é o do Estado Democrático de Direito, em que os cidadãos adquirem direitos de participação política através do direito de voto, universal e igual, e do reconhecimento da liberdade de organização e pertencimento a associações e partidos políticos. Também aqui, o mundo da vida se faz valer frente aos imperativos de uma estrutura de poder que se abstrai de todos os contextos concretos desse mundo.

Finalmente, o Estado Social e Democrático de Direito, cuja 'juridificação' espelha um certo equilíbrio de poder dentro de um âmbito de ação já constituído juridicamente, procurando absorver os efeitos externos do processo de produção baseado no trabalho assalariado. Contudo, para se pensar mais a fundo o processo de colonização interna do mundo da vida, vale chamar a atenção para o fato de que, ao mesmo tempo que o Estado Social intensifica ainda mais a aplicação de mecanismos de proteção ao mundo da vida reestruturado pelos imperativos sistêmicos, ele procede de forma a privar a liberdade dos seus beneficiários. Isso ocorre devido ao fato de que ao estabelecer uma rede de relações de clientela, o Estado Social volta a mediar o funcionamento do mundo da vida, desintegrando âmbitos até então comunicativamente estruturados. 
Habermas exemplifica esse fenômeno com o caso da aplicação dos princípios do Estado de Direito nas relações entre a familia e a escola na Alemanha:

'Por esta via, estes âmbitos de ação ficam abertos às intervenções burocráticas e aos controles judiciais. A família e a escola não são de modo algum âmbitos de ação formalmente organizados. Nestas esferas do mundo da vida, anteriormente a toda 'juridificação', existem normas e nexos de ação que de modo funcionalmente necessário dependem do entendimento como mecanismo de coordenação da ação. A 'juridificação' dessas esferas não significa, portanto, o adensamento de uma rede já existente de relações formais, mas uma complementação $e$ sanfão levadas a efeito não por meio de instituicões jurídicas, mas através do direito como meio de controle" (Habermas, 1990, p. 522)".

Há, assim, uma 'desmundanização' da convivência familiar e escolar, que agora fica regulada formalmente.

É só nesse contexto que faz sentido pensar os movimentos sociais como organizações de cidadãos que reagem ao processo de colonização interna do mundo da vida. Os movimentos sociais movem-se no interior da esfera pública impondo-se frente às pressões do Estado Social cuja lógica de funcionamento procura reduzir os cidadãos a uma mera clientela de beneficiários e a eleitores legitimadores da dominação política nos processos democráticos de formação da vontade política (já que a luta dos partidos no processo eleitoral pode transformar os votos em 'hipotecas de legitimação'). Nessa lógica, “a burocratização se apodera dos processos espontâneos de formação da opinião e da vontade coletivas e os esvazia de conteúdo" (Habermas, 1990, p.461). É sobre a reação dos movimentos sociais a esse processo que falaremos a seguir. 


\section{MOVIMENTOS SOCIAIS: A ESFERA PÚBLICA EM REAÇÃO À COLONIZAÇÃO SISTÊMICA DO MUNDO DA VIDA}

A colonização do mundo da vida pelo sistema é central para a emergência dos chamados novos movimentos sociais ${ }^{2}$. A compreensão da análise habermasiana a esse respeito depende da aceitação de que somente os âmbitos de ação que cumprem funções econômicas e políticas podem ficar regulados pelos meios de controle dinheiro e poder. No momento em que esses meios transbordam as esferas sistêmicas atuando nos âmbitos de reprodução cultural, de integração social e de socialização - âmbitos, portanto, comunicativamente estruturados -, o resultado é o aparecimento de 'patologias laterais': perda de sentido, perturbações da identidade coletiva, anomia, perda de motivação, crise de orientação, alienação, psicopatologias, perda de tradições, e outras.

Habermas lembra que nas sociedades avançadas do Ocidente, desde a década de 60 , um número considerável de conflitos foi gerado fora do âmbito da reprodução material e da distribuição. Além disso, tais conflitos não foram e não são canalizados por partidos e associações, não sendo possível apaziguá-los através de recompensas que estejam em conformidade com o sistema. As suas origens estão nos 'pontos de sutura' entre sistema e mundo da vida. Suas lutas significam uma reação aos 'déficits comunicativos' que a reprodução cultural, a integração social e a socialização sofrem com os processos de reificação. De forma geral,

"a prática dos movimentos alternativos se dirige contra a institucionalização do trabalho profissional para fins de lucro, contra a mobilização da força de trabalho por pressões do mercado, contra a extensão da compulsão à competitividade. Também se dirige contra a monetarização dos serviços, das relafões e do tempo, contra a redefinição consumista dos âmbitos da vida privada e dos estilos de vida pessoal.

${ }^{2}$ Ver Cohen (1985) para uma definição mais precisa dos novos movimentos sociais. 
Exigem, além disso, que cesse o atual tipo de relação dos clientes com os organismos públicos e que eles se organizem participativamente" (Habermas, 1990:560-1).

Exatamente por isso não podem ser apaziguados por compensações financeiras ou por mecanismos burocráticos.

'Em uma palavra: os novos conflitos se desencadeiam não em torno de problemas de distribuifão, mas em torno de questões relativas à gramática das formas de vida.'(Habermas, 1990, p. 556)

É nesse sentido que o autor aponta para a diferença entre a velha política, centrada em torno de questões de seguridade social e econômica, e a nova política, ligada a questões de qualidade de vida, de igualdade de direitos, de autorealização individual, de participação e de direitos humanos.

Vale aqui chamar a atenção para a consideração que Cohen (1985) faz a respeito dessa proposta analítica de Habermas. Para ela, ainda na Teoria da Afão Comunicativa e em estudos temporalmente próximos a essa obra, os movimentos sociais aparecem somente como reajões defensivas contra a penetração do Estado e do mercado na vida social; com exceção do feminismo, os novos movimentos sociais são vistos somente como formas de resistência e retraimento que buscam conter o movimento dos sistemas de ação formalmente organizados. Para Cohen, apesar deles significarem a continuada capacidade do mundo da vida de resistir à reificação, Habermas não os vê como portadores de uma nova identidade coletiva, como sendo capazes de institucionalizar os potenciais positivos da modernidade ou de transcender políticas particularistas e expressivas.

Também Avritzer (1993) sugere que a limitação de Habermas em entender a esfera pública apenas como defesa do mundo da vida põe em dúvida a capacidade dela redefinir a relação entre o público e as esferas de exercício da autoridade, capacidade esta constitutiva da própria noção 
de público. No próximo item, desenvolveremos mais cuidadosamente as alternativas dessas críticas.

À luz dessas considerações, é possivel melhor compreender a diferenciação proposta por Habermas entre os movimentos com potenciais de emancipafão e os movimentos com potencial de resistência e de retirada. $\mathrm{O}$ movimento feminista é um exemplo de potencial emancipatório na medida em que luta, não só pelo estabelecimento da igualdade formal de direitos - com a eliminação de privilégios masculinos -, mas também pela revolução de formas de vida concretas marcadas por monopólios masculinos.

Como exemplo para os movimentos de resistência, citamos aqui o caso dos ambientalistas que, para o autor, não são, na sua essência, uma reaçào aos efeitos da grande indústria sobre o equilíbrio ecológico, à drástica diminuição dos recursos naturais não-renováveis e à evolução demográfica já que tais problemas são, em princípio, abstratos, exigindo, por isso, soluções técnicas e econômicas a serem tomadas por meios administrativos. De acordo com Habermas,

"o que provoca o protesto é mais a intensiva destruição do entorno urbano, os destroços urbanisticos, a industrialização e a contaminação da paisagem, as seqüelas médicas das condigões da vida moderna, os efeitos secundários da indústria farmacêutica, etc., isto é, evoluções que, de forma notória, atentam contra as bases orgânicas do mundo da vida e que, como contraste, nos fazem conscientes da existência de critérios de habitabilidade, de que a não satisfasão das necessidades estéticas de fundo tem limites"(Habermas, 1990, p.559).

O caso dos movimentos 'psicologizantes' e de renovação do fundamentalismo religioso são ainda mais notáveis para se perceber a reação decorrente do empobrecimento das práticas comunicativas e da substituição delas pelos meios de controle. Nesses movimentos, características como gênero, idade, cor, grupos de vizinhança, religião, acabam servindo à construção e delimitação de comunidades de comunicação que se au- 
toprotegem em forma de subculturas, de maneira a garantir as condições para o desenvolvimento de identidades pessoais e coletivas. A revalorização daquilo que é particular, antigo, provinciano, atividades informais, reuniões de conversas, interações simples e espaços de opinião pública, significa tentativas de fomentar e revivificar possibilidades de expressão e comunicação que não existem mais.

Assimilando as críticas feitas por Cohen (1985) e Avritzer (1993), pode-se dizer que o potencial da Teoria da Ação Comunicativa para a elaboração de um novo modelo normativo de democracia 'emperra' na não consideração dos movimentos sociais e outras organizações da esfera pública como atores de sua institucionalização. Não queremos dizer com isso que Habermas não tenha refletido sobre tal modelo: na própria Teoria da Ação Comunicativa ele defende que o uso do direito como meio de controle deveria ser substituído por procedimentos de regulação dos conflitos que se ajustassem às estruturas da ação orientada ao entendimento. Isso se daria através de processos de formação discursiva da vontade individual e coletiva e através de procedimentos de negociação e decisão orientados para o consenso. Essas reflexões aparecem melhor fundamentadas em seu trabalho "Three Normative Models of Democracy" (1994), como será possível ver a seguir. Contudo, esse aspecto particular sensibilizou alguns autores que procuraram redefinir alguns aspectos da teoria de Habermas para tornar seu instrumental analítico apto para a consideração dos movimentos sociais e outras organizações da sociedade como atores primordiais na luta pela institucionalização desse novo modelo normativo. É o que também veremos a seguir.

\section{A Esfera PÚblica E o NOVO MODELO NORMATIVO DE DEMOCRACIA}

Levando adiante o potencial que a Teoria da Ação Comunicativa tem para a elaboração de um modelo normativo de democracia que leve em 
conta a reflexividade, própria da modernidade, Habermas apresenta o que ele chama de modelo 'proceduralist' (Habermas, 1994). As reflexões do autor a respeito desse modelo têm como referência os já conhecidos modelos liberal, ou lockeano, e comunitário, ou republicano, a partir dos quais, e acrescentando a eles aspectos centrais de sua teoria, o modelo 'proceduralist'é elaborado.

De acordo com o autor, no modelo liberal de democracia, parte-se do pressuposto de que a sociedade é como um mercado estruturado de uma rede de interações entre pessoas privadas, detentoras de direitos privados. ${ }^{3}$ Assim, os cidadãos lutam por interesses privados dentro de limites determinados por estatutos legais. O voto é o meio através do qual os cidadãos têm a oportunidade de defender seus interesses privados, escolhendo parlamentares e governantes que irão representá-los. É essa escolha que fará o impacto sobre a administração. Aqui, a relação dos indivíduos na esfera pública é determinada pela competição de coletividades agindo estrategicamente, tendo em vista a manutenção ou conquista de posições de poder. $\mathrm{O}$ interessante é que, conforme Habermas, nesse modelo as escolhas políticas dos cidadãos têm a mesma estrutura das escolhas dos participantes no mercado. "O modelo liberal se sustenta não numa autodeterminação democrática de cidadãos deliberantes, mas na institucionalização legal de uma sociedade econômica" (Habermas, 1994, p.7).

O modelo comunitário, por sua vez, parte do pressuposto da existência de uma base autônoma na sociedade, independente da administração pública e do mercado, que evita que a comunicação política seja 'engolida' por um aparato governamental ou ainda que seja assimilada pelas estruturas de mercado. Por isso, a autoridade governamental, nesse modelo, emerge dos cidadãos, do poder produzido comunicativa-

'Vale lembrar aquele segundo momento de 'juridificação' apontado por Habermas, próprio do Estado Burguês de Direito, apresentado no item Evolução Sistêmica e Mudança Institucional. 
mente na práxis da autolegislação dos cidadãos - já que os cidadãos são dotados efetivamente de direitos de participação política comunicativa. A política aparece, então, como sendo dotada de uma função que transcende a mera mediação de interesses privados: ela é mais constitutiva para os processos sociais na medida em que os membros da sociedade tomam consciência de sua interdependência, fundando a solidariedade e a orientação para o bem comum como uma terceira fonte de integração social - ao lado da administração e do mercado. A vantagem apontada por Habermas desse modelo em relação ao liberal é que ele "preserva o significado original de democracia em termos de institucionalização do uso público da razão exercida conjuntamente por cidadãos autônomos" (Habermas, 1994, p.3).

Contudo, o problema do modelo comunitário está na grande probabilidade dele manter-se provinciano, no sentido de ter seu funcionamento restringido a aspectos éticos. Nessa visão comunitária, o processo democrático passa a depender das virtudes de cidadãos devotados para o bem comum, acreditando-se haver uma conexão necessária entre o conceito de democracia deliberativa e comunidade ética integrada. Nesse sentido, o indivíduo toma conhecimento das questões que divide com outras pessoas somente na medida em que compartilha com elas as mesmas tradições e os mesmos processos de formação.

Conforme Habermas, esse 'auto-entendimento ético coletivo' é anacrônico em relação à própria função dos processos legislativos, que é a de regulamentar questões de forma que elas tenham uma validade universal, e não somente validade para uma comunidade específica.

É a partir desses elementos que Habermas apresenta o novo modelo normativo 'proceduralist' de democracia: há, aqui, uma valorização da normatividade com uma intensidade maior em relação ao modelo liberal, mas menor em relação ao modelo comunitário já que, apesar de concordar com a importância da centralidade do processo normativo de formação da vontade, não coloca a constituição como secundária: nesse mo- 
delo, o sucesso da política deliberativa depende não unicamente da atuação coletiva dos cidadãos, mas de uma institucionalização dos procedimentos e condições da comunicação. Para Habermas, é importante que se tenha em mente que um tipo legítimo de 'barganha' política depende de uma pré-regulamentação de termos justos para a busca de resultados, termos estes que sejam aceitáveis para todas as partes sobre a base de suas diferentes preferências - diferenças essas, vale lembrar, típicas da modernidade, $\mathrm{em}$ que as visões de mundo unificadoras e orientadoras das ações já perderam seu caráter globalizante e totalizante, como em 'tempos anteriores'.

Dessa forma, esse modelo insiste no fato de que o processo de formação da vontade não retira sua força legitimadora de uma prévia convergência de um conjunto de convicções éticas, mas sim, de pressupostos comunicativos que permitam que os melhores argumentos prevaleçam, e de procedimentos que assegurem processos justos de barganha.

Uma vez estabelecidos os pressupostos comunicativos, Habermas coloca que a intersubjetividade dos processos de comunicação fluirão tanto através dos corpos parlamentares como das redes informais da esfera pública. Isso porque tais redes poderão gerar influência que se transformará em força comunicativa através de canais de eleições políticas. As conseqüências desse novo procedimento, acredita o autor, forçarão um rebalanceamento das três fontes de integração social das sociedades modernas - dinheiro, poder e solidariedade -, fazendo com que a solidariedade ganhe primazia sobre as duas outras na função de integração social.

A questão que se coloca é: se Habermas não aponta para um ator que leve adiante a implementação desse novo modelo, como vislumbrar, numa sociedade caracterizada por fortes disparidades de poder político e econômico, a possibilidade de a solidariedade suplantar o dinheiro e o poder na determinação da dinâmica social, superando, com isso, a predominância dos âmbitos de ação com respeito a fins, cuja lógica tende, cada vez mais, a submeter o mundo da vida a seus imperativos? Nova- 
mente aqui, não aparece nenhuma indicação de que os movimentos sociais e/ou outras organizações da esfera pública tenham condições de levar adiante essa transformação.

Cohen (1985) atribui essa 'fenda' nas reflexões de Habermas ao fato do autor ter feito, na Teoria da Ação Comunicativa, uma análise incompleta da sociedade civil e, com isso, não ter podido incorporar novas categorias analíticas. É a partir desse aspecto que Cohen, Arato e Avritzer trabalham. A incorporação do conceito de sociedade civil no instrumental analítico habermasiano significa pensar na possibilidade de conciliação entre o papel desempenhado pelo mercado e pelo Estado e o fortalecimento de uma terceira arena, uma esfera pública independente $\mathrm{e}$ separada de toda forma de comunicação oficial, estatal ou controlada pelos partidos (Avritzer, 1993 e Arato, 1995). Abre-se espaço, portanto, para a idéia de que o ponto central para um novo modelo de sociedade não é mais a reestruturação do Estado a partir de um novo princípio mas sim a "redefinição das relações entre Estado e sociedade sob o ponto de vista desta última" (Avritzer, 1993, p.213).

O 'conceito habermasiano de sociedade civil' é, então, elaborado por Cohen e Arato a partir da distinção, no interior do mundo da vida, de duas dimensões: uma primeira ligada ao reservatório de tradições imersas na linguagem e na cultura, e uma segunda dimensão, de cunho institucional, envolvendo aparatos que não podem ser ligados nem aos estoques de tradições disponíveis nem aos mecanismos sistêmicos de coordenação da ação. É essa última dimensão do mundo da vida que os autores identificam como sendo a sociedade civil (Avritzer, 1993).

Mostrando o perfil ofensivo conferido à esfera pública - diferentemente do caráter defensivista que os movimentos sociais têm em Habermas -, Cohen e Arato entendem que os movimentos sociais e outras instituições sociais podem criar novas formas de mediação entre os subsistemas economia e administração e o mundo da vida através da constituição de formas institucionais permanentes de limitação do mercado e 
do Estado. Podem criar fóruns intermediários entre o mercado, o Estado e a sociedade civil com o objetivo de propor soluções entre os conflitos que se dão no enfrentamento das duas lógicas diferentes de funcionamento dos âmbitos de ação. $\mathrm{O}$ aspecto essencial dessas novas formas institucionais é que:
"A forma de operą̧ão destes mecanismos seria o direito reflexivo ou a pós-regulagãa. Tanto o direito reflexivo quanto a pós-regulafãa multi- plicariam a substituifão do intervencionismo do Estado de bem-estar social por um processo de constituição externa que restringe a interven- fão do Estado ao cumprimento de um número minimo e pré-definido de principios legais. A intervencão estatal (...) é, deste modo, substi- tuida pela criação de normas de procedimento, organização e regulagãa que possam levar os próprios atores a alterar a sua postura no interior das formas societárias de negociagáa.o."(Avritzer, 1993, p. 221)

Num trabalho recente, Arato (1995) avança em algumas questões que emergiram em seus estudos a respeito do 'conceito habermasiano de sociedade civil' tendo em vista análises que focalizaram experiências históricas reais. De acordo com o autor, as associações e organizações sociais - que, sem dúvida nenhuma convergem no importante aspecto de funcionarem sob uma mesma lógica normativa comunicativa de coordenação da ação - apresentam sensiveis diferenças no tocante ao tamanho, extensão temporal e espacial, papel político dos grupos informais e outros. Tais associações, por sua vez, distinguem-se dos movimentos sociais em razão do nível de organização, do número de questões discutidas, do papel dos interesses, do processo de formação de identidades. A questão que, diante disso, nos aparece é: como poderiam, a despeito de todas essas diferenças, constituir-se como um sujeito politico coeso, capaz de uma modificação institucional tão drástica como a apontada por Habermas? O próprio Arato (1995) afirma que a experiência de alguns países do leste europeu que passaram pela transição demo- 
crática em fins da década de 80 , início dos anos 90 , - nos quais os movimentos e iniciativas sociais cram $\mathrm{c}$ ainda são muito ativos - mostrou que a sociedade civil, sozinha, não foi capaz de realizar uma mudança de regime político, tanto no âmbito de uma estratégia de mudança limitada quanto no de uma estratégia revolucionária. Segundo o autor, essa tarefa esteve, fundamentalmente, nas mãos das elites, das contra-elites, ou dos partidos.

No entanto, apesar dessas ponderaçōes, Arato diz não acreditar que durante o processo de transição para regimes democráticos, o deslocamento da tarefa de negociação da sociedade civil para a sociedade política signifique uma total desmobilização da esfera pública organizada. Ao contrário disso, o autor entende que a estabilização da democracia e os projetos futuros de democratização dependem do desenvolvimento de uma relação complexa entre as esferas civil e política, relação esta que, sem dúvida, aponta para a elaboração de novos mecanismos que permitam uma expansão dos âmbitos de ação estruturados comunicativamente.

\section{CONSIDERAÇÕES FINAIS}

Certamente, não há ainda uma elaboração teórica definitiva que possa iluminar de forma mais precisa as questões e os problemas anteriormente levantados. Sabe-se que Habermas vem preparando um estudo com o provável título Facticity and Validity ${ }^{4}$ que se aprofunda sobre questões relativas ao direito reflexivo e às novas formas de instituições que concretizem o potencial reflexivo da modernidade. De qualquer forma, os elementos anteriormente apresentados já nos permitiram algumas reflexões e inquietações; as questões que podem sugerir novas reflexões são: como uma mudança institucional tão drástica, como a sugerida por Habermas, pode ser pensada para um país como o Brasil? Há,

${ }^{4}$ Conforme indicação de Arato (1993).

Temáticas, Campinas, 4(8):143-166, jul./dc\%. 1996 
atualmente, experiências que apontam para essa direção? Arato (1995) propõe, como um estudo a ser realizado, a análise do papel das várias organizações da sociedade civil no processo de elaboração de constituições e nos processos de tomada de decisão locais de forma a verificar em que medida: tem sido propostos novos canais de participação; tem sido possivel descentralizar efetivamente o processo decisório. Talvez o estudo de experiências como a do orçamento participativo ou ainda da gestão participativa de recursos hídricos seja interessante para avançar nessas questões.

Trata-se de uma tarefa que realmente pode nos mostrar o potencial real da sociedade civil na defesa dos âmbitos de ação estruturados comunicativamente, tão fundamentais para o processo de reprodução cultural, integração social e socialização, mas também o potencial ofensivo dessas organizações no que se refere a efetivação do caráter reflexivo que traz a modernidade, possibilitando a tão almejada emancipação do ser humano, possibilitando, finalmente, sua autodeterminação. Se a realidade social é mais habermasiana do que horkheimeriana, só análises desse tipo poderão melhor nos esclarecer.

ABstract: Jürgen Habermas' The Theory of Communicative Action is a precious theoretical tool to analise the order of events in the contemporary world. His ambicious analytical propositions come accompanied by a model of radical democracy that contemplates the constitution of the political public sphere upon new bases, dynamized by new mechanisms and oriented to different ends. The aim of this article is to discuss how this Habermasian model, enlarged by Andrew Arato and Jean Cohen's contributions on the theory of civil society, can be applied to the study of new social moviments envolved in the construction of such a model of radical democracy.

KEYWORDS: communicative action; democratic theory; new social moviments. 


\section{REFERÊNCIAS BIBLIOGRÁFICAS}

ADORNO, T. Capitalismo Tardio ou Sociedade Industrial. In: COHN, G. (org). Adorno - Colefão Grandes Cientistas Sociais. São Paulo: Ática, 1986, p.62-75.

ARATO, A. Ascensão, declínio e reconstrução do conceito de sociedade civil - orientações para novas pesquisas. Revista Brasileira de Ciências Sociais, $\mathrm{n}^{\circ}$ 27, 1995, p. 18-27.

ASSOUN, P.L. A Escola de Frankfurt. São Paulo: Ática, 1991.

AVRITZER, L. Além da dicotomia Estado/Mercado - Habermas, Cohen e Arato. Novos Estudos Cebrap, São Paulo, nº36, 1993, p.213-222. COHEN, J. Strategy and Identity: new theoretical paradigms and contemporary social movements. Social Research, Nova Iorque, v.52, $\mathrm{n}^{\circ}$ 4, 1985, p.663-716.

FREITAG, B. A Teoria Critica: ontem e hoje. São Paulo: Brasiliense, 1986.

HABERMAS, J. Teoria de la Accion Comunicativa. 2 Tomos. Buenos Aires: Taurus, 1990.

HABERMAS, J. Three Normative Models of Democracy. Constellations, v.1, $\mathrm{n}^{\circ} 1,1994, \mathrm{p} .1-10$.

HORKHEIMER, M. Eclipse da Rąão. Rio de Janeiro: Labor do Brasil, 1976.

HORKHEIMER, M., ADORNO, T. Dialética do Esclarecimento. Rio de Janeiro: Jorge Zahar, 1985.

MARCUSE, H. One-Dimensional Man. Boston: Beacon Press Boston, 1968.

MARX, K., ENGELS, F. A Ideologia Alemã (Fenerbach). São Paulo: Hucitec, 1991. 